\title{
Effects of Stabilization Exercise on the Structural Characteristics of Trunk Muscles between Stable and Unstable Surfaces
}

\author{
Jae-Cheol Park', Jae-Young Yu², Tae-Yeon Hwang ${ }^{1}$, Chan-Kyu Kim³ ${ }^{3}$ Jin-Gyu Jeong ${ }^{1}$ \\ 'Department of Physical Therapy, Chunnam Techno University Gokseong-gun, Jeollanam-do; ${ }^{2}$ Department of Physical Therapy, Graduate School of \\ Dongshin University; ${ }^{3}$ Department of Physical Therapy, Gwangju Health University, Gwangju Korea
}

Purpose: This study was conducted to evaluate the effects of bridge exercise on the structural characteristics of trunk muscles in patients with lumbar pain by applying the exercise on either a stable or an unstable surface.

Methods: Thirty subjects participated in the experiment and were randomly divided into an unstable bridge exercise group (UBEG) and a stable bridge exercise group (SBEG). The exercise program for each group was conducted three times a week over a six-week period. The structural characteristics of trunk muscles were measured by obtaining images using an ultrasound imaging device.

Results: The thicknesses of the external oblique (EO), internal oblique (IO), and transverse abdominis (TrA) and the fiber angle of the erector spinae (ES) in the UBEG and the SBEG showed statistically significant increases in all items measured after the experiment. A comparison of groups conducted after the experiment to determine the effects of the exercise on each group showed no significant differences between groups for any of the measured items.

Conclusion: A comprehensive review of the study results showed statistically significant increases in the thicknesses of the EO, I0, and TrA and the fiber angle of ES in both the UBEG and the SBEG. While the comparison of the groups with respect to the effects of the exercise revealed no significant differences, there were relatively larger effects in the UBEG than in the SBEG.

Keywords: Bridge exercise, Muscle thickness, Fiber angle, Ultrasound imaging device

\section{서 론}

요통의 중요한 원인 중 하나는 허리부위(lumbar segment)의 불안정 성이며, ${ }^{1}$ 허리 손상의 예방과 치료를 위해서는 척추의 안정성이 먼저 이루어져야 하고, 척추의 안정성을 얻기 위해서는 몸통 근육들의 동 시수축(co-activation)은 가장 중요한 요소이다. ${ }^{2}$ 또한 운동성 저하로 허리부위의 유연성이 떨어지고 근력이나 근지구력이 약화되는 요통 환자의 경우 통증과 허리 근육의 피로도 증가로 이어질 수 있어 요통 개선을 위해서는 허리 근력의 강화가 필수적인 것으로 알려져 있다. ${ }^{3}$

척추 주변 근육의 강화를 통해 척추의 안정성을 회복시킬 수 있는 허리 안정화 운동 ${ }^{4}$ 은 골반경사운동, 네발기기운동, 복부 당기기(abdominal hollwing), 교각운동 등이 있다. ${ }^{5}$ 허리 안정화 운동 중에서 효 과적으로 보고되고 있는 교각운동(bridging exercise) $)^{6-8}$ 은 허리 엉치 부위의 안정화 운동으로 자주 사용되며, 작은 근육과 큰 근육을 적
절한 비율로 활성 시켜 근육의 협력 패턴을 재교육하는 운동이다. ${ }^{2}$ 교각운동은 요통 환자를 위해 물리치료실에서 많이 실시 되어지고 있으며, 치료사들이 환자에게 교육하기도 쉬워 환자들이 집에서도 운동할수 있도록 많이 처방되고 있다.

여러 가지 교각운동 중에서 안정면(stable surface)과 같은 정적인 (static) 환경보다는 불안정면(unstable surface)인 치료용 공 위와 같은 동적인(dynamic) 환경에서 몸통의 중심 안정화 운동(core stability exercise)을 수행하는 것이 고유수용기를 자극하여 대뇌의 운동기관에 자극을 주어 균형감각과 균형유지 능력을 극대화시킨다고 하였다. ${ }^{9}$ Haynes $^{10}$ 는 다양한 불안정판 기구(unstable platform device)를 이용한 여러 가지 자세에서 몸통의 안정화 운동을 제시하였으며, Melnick ${ }^{11}$ 는, 안정된 면보다 불안정면에서의 동작이 근육의 활성도를 향상시 킨다고 하였다.

뼈대근육의 기능 중 근력은 근육이 발휘할 수 있는 최대의 힘이라 
고 정의 되어지는데, 근력에 영향을 미치는 인자로 구조적 특성인 횡 단면적12,13 및 근 체적 ${ }^{4}$ 등이 검토되어 왔으며, 근 횡단면적은 최대 수 의적 등척성 수축력(maximal voluntary isometric contraction, MVIC) 을 결정하는 하나의 중요한 인자로 오래전부터 인식되었다.12,15 근육 의 사용을 제한할 때 근육 크기 감소에 비례해서 근력의 손실이 나타 나므로 근력과 근육의 두께는 높은 상관관계를 가지는 것으로 볼 수 있다. ${ }^{16}$ 근육의 구조는 섬유 속 길이와 섬유의 각도를 포함한 근육다 발의 형태 및 구조적 배열을 의미한다. ${ }^{17}$

근육의 구조적인 특성인 근 섬유의 크기나 두께, 섬유 형태 등을 파악하기 위해 많은 연구들이 지속되어 왔으며, ${ }^{18}$ 현재는 과학기술의 발달과 최첨단 장비가 개발됨에 따라 초음파 영상, 자기공명영상, 컴 퓨터 단층촬영 등을 활용하여 근육의 구조적 특성을 평가하고 있다. 그 중 초음파는 실시간으로 적용할 수 있는 장비로 심부 구조의 측정 에 꼭 필요한 장비이며, ${ }^{19}$ 뼈대근육의 구조적 특성에 대한 질적이고 양적인 분석에 사용된다. 그리고 연부조직의 구조적 완전성과 형태 학적 특성을 평가하기 위해 사용되는데 정적, 동적 상태에서 근 두께 변화와 근섬유의 단면적 변화, 근육영상밀도 변화 등을 시각화하여 정량적으로 평가할 수 있다. ${ }^{20} \mathrm{McMeeken} \mathrm{등른} \mathrm{초음파로} \mathrm{측정한} \mathrm{배}$ 근육의 두께와 근전도 상의 근육의 활성화는 유의한 상관관계가 있 어 초음파로 확인된 근육의 두께 변화는 근 수축의 척도로 사용할 수 있다고 하였으며, Christensen 등22은 근육의 두께를 측정하는 기구 로서 초음파 사용은 신뢰도가 높다 하였다.

근육의 섬유 형태는 신체 자세 및 관절의 움직임에 의해 영향을 받 을 수 있는데 허리 폄 근육의 섬유각도는 굽힘 시 감소하는 것으로 나타났으며, ${ }^{23} \mathrm{Singh}$ 등 ${ }^{24}$ 은 노인의 허리 폄 근육의 섬유각도에서 유의 한 감소가 있었고, 선자세에서 허리 폄 근육의 섬유각도와 근력 간의 상관성이 있다고 하였다.

많은 선행 연구에서 불안정 지지면에서 교각운동이 안정적 지지면 보다 효과적인 운동 방법임이 증명되었지만, $25-28$ 지지면에 따른 효과 차이가 없다는 연구도 적지 않다.29.31 그리고 섬유각도에 대한 선행 연 구가 많이 부족한 실정이다. 따라서 본 연구는 교각운동을 안정면 (stable surface)과 불안정면(unstable surface)으로 나누어 요통 환자에 게 적용한 후 배바깥빗근(external oblique, EO), 배속빗근(internal oblique, $\mathrm{IO}$ ), 배가로근(transverse abdominis, $\operatorname{Tr} \mathrm{A}$ )의 두께와 척추세움 근의 섬유각도(erector spinae muscles fiber angle)에 어떠한 영향을 미 치는지 알아보고자 하였다.

\section{연구 방법}

\section{1. 연구대상}

본 연구는 연구 실시기관의 임상연구윤리위원회(1041557-201503-
Table 1. General characteristics of subjects $(\mathrm{N}=30)$

\begin{tabular}{lrrr}
\hline & UBEG $(n=15)$ & SBEG $(n=15)$ & \multicolumn{1}{c}{$p$} \\
\hline Age (year) & $49.0 \pm 4.99$ & $50.3 \pm 5.06$ & 0.496 \\
Height $(\mathrm{cm})$ & $158.1 \pm 4.50$ & $155.0 \pm 5.52$ & 0.102 \\
Weight $(\mathrm{kg})$ & $55.2 \pm 9.16$ & $57.5 \pm 6.21$ & 0.411 \\
\hline
\end{tabular}

UBEG: unstable bridge exercise group, SBEG: stable bridge exercise group

HR-004-01)의 심의를 거쳐 연구승인을 받은 후 실시하였다. 00지역의 병원에서 물리치료를 받고 있는 만성 요통환자 30 명을 대상으로 하 였으며 대상자의 선정기준은 연령 40-50대의 요통 환자로 유병기간 6 개월 이상이며, X-ray 검사를 통해서 만성 요통 진단을 받은 환자로 선정하였다. 정형 외과적 문제로 척추 수술 경험이 있는 자 그리고 운 동 프로그램을 수행할 수 없는 자는 대상자에서 제외하였다. 연구를 시작하기 전 연구의 목적과 방법을 설명하였고, 연구 참여자의 동의 서를 작성한 후 본 연구를 시작하였으며, 불안정 지지면에서의 교각 운동군(unstable bridge exercise group, UBEG) 15명, 안정적 지지면에서 의 교각 운동군(stable bridge exercise group, SBEG) 15 명으로 나누어 진행되었다. 실험 대상자의 분류는 연구자의 임의 배정 방식에 의하 여 무작위로 설정되었으며, 실험 전 동질성 검정 결과 연령, 신장, 체중 에서 유의한 차이가 없어 동일한 집단임이 확인되었다(Table 1).

\section{2. 실험방법}

\section{1) 운동방법}

1) 안정적 지지면에서의 교각운동은 팔꿈치를 $90^{\circ}$ 로 구부리고 엎드 린 상태에서 팔꿈치와 발가락을 이용하여 몸을 지탱하였다. 목은 부 드럽게 펴고 시선은 바닥을 향하게 하였다. 2) 안정적 지지면에서의 교각운동은 바로 누운 상태에서 무릎관절을 90 도 구부리고 손은 바 닥에 대고 양팔은 30 도 벌린다. 머리와 목은 똑바로 하고 눈은 천장 을 바라본다. 우세측 다리 한쪽을 들어 한다리로 버티고 어깨빼가 바 닥에서 떨어지도록 골반을 들어 올린다. 3) 불안정 지지면에서의 교각 운동은 1) 안정적 지지면에서의 교각운동과 같은 방법으로 하고 팔 꿈치와 발가락 밑에 공기 쿠션(TOGU, Germany)을 적용하였다. 4) 불 안정 지지면에서의 교각운동은 2) 안정적 지지면에서의 교각운동과 같은 방법으로 하고 발바닥 밑에 공기 쿠션을 적용하였다. 그룹별 운 동 프로그램은 20 초 운동, 30 초 휴식을 1 세트로 하여 20세트를 주 3 회, 6 주간 실시하였다. 운동의 시작과 끝 5 분간은 준비 및 마무리 운 동으로 허리부위에 대해 스트레칭을 하였다.

\section{2) 측정방법}

(1) 초음파 측정

근육의 두께 측정 및 디지털 영상분석을 위해 초음파 영상 장치를 (Mylabone, Esaote, Italy) 이용하여 측정하였다. 이 장치의 주파수 변조 
범위는 $10 \mathrm{MHz}$ 로 하였고 초음파 변환기는 $7.5 \mathrm{MHz}$ 직선형변환기 (linear transducer)를 사용하였다. 검사자 간의 차이를 최소화하기 위 해 배 근육의 기본적인 해부학 지식과 초음파 검사에 숙달된 물리치 료사 1 인의 측정자가 검사하였다. 배 근육 두께 측정은 대상자가 바 로 누운 자세에서 무릎관절 아래 삼각형 모양의 받침대를 받치고 측 정 시 자세가 고정될 수 있도록 하였으며, 배 근육의 오른쪽 부위만 측정하였다. 또한 배가로근의 두께 변화 양상에 호흡 주기가 영향을 미칠 수 있다는 Hodges와 Gandevia ${ }^{32}$ 의 연구결과에 따라 호기의 마지 막 단계에서 배바깥빗근, 배속빗근, 배가로근을 측정하였다. 피부의 압박을 최소화 하기 위해 충분한 양의 초음파 겔(Dayo Medical, Co. PROGEL-II, Korea)을 변환기와 피부 사이에 도포하였고, 변환기를 엉 덩뼈 능선의 상단부에 가로로 위치시키고 복부의 중앙 쪽으로 이동 하면서 배바깥빗근, 배속빗근, 배가로근을이 모두 뚜렷하게 보일 때 화면을 저장하였다. 배바깥빗근, 배속빗근, 배가로근의 두께측정은 배속빗근의 근막과 배가로근의 근막이 만나는 지점으로부터 $13 \mathrm{~mm}$ 떨어진 지점을 측정하였다. ${ }^{33}$ 초음파 영상장치에 내장된 전자 캘리퍼 를 이용하여 근막과 근막 사이를 3 회 반복 측정한 후 평균값을 근육 의 두께로 정하였다. 측정 시기별 측정부위를 정확히 유지하기 위해 수술용 펜으로 표시한 후 시행하였다.

척추 세움근의 섬유 각도는 편안히 선 상태에서 제 3 허리뼈 레벨에

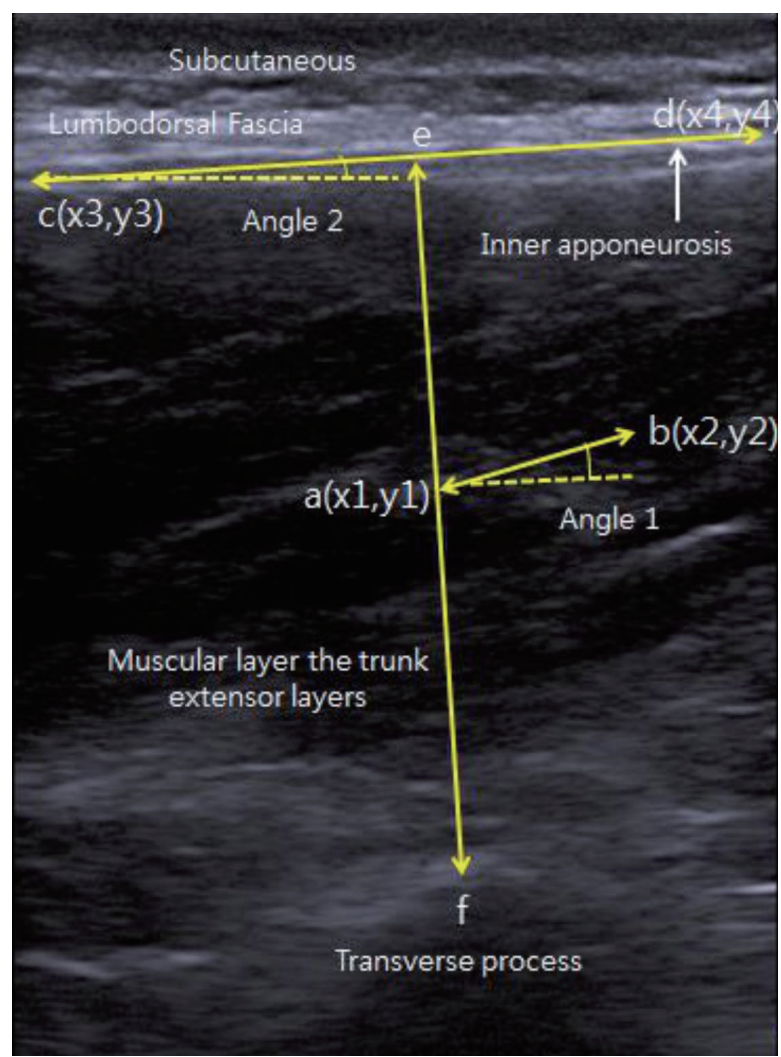

Figure 1. Determination of fiber angles of the erector spinae muscle.
서 오른쪽 부위만 측정하였다. 변환기를 엉치뼈에서 척주의 중심선 에 세로 방향으로 배치하여 제 3 허리뼈 가시돌기가 확인될 때까지 위 쪽으로 이동시킨 후 가로돌기의 이미지가 식별될 때까지 변환기를 약 $3-4 \mathrm{~cm}$ 오른쪽으로 이동시켜 초음파 영상을 획득하였다.24

\section{(2) 섬유각도측정}

획득한 초음파 영상은 Image Pro Plus 4.5 (Media Cybernetics, USA) 프로그램을 사용하여 섬유 각도를 측정하였다. $\mathrm{f}$ 는 시각적으로 식별 되는 가로돌기의 중간지점이고, $\mathrm{f}$ 에서 근막과 수직을 이루는 점(e)을 연결한 선이 ef이다. $\mathrm{a}\left(\mathrm{x}^{1}, \mathrm{y}^{1}\right)$ 와 $\mathrm{b}\left(\mathrm{x}^{2}, \mathrm{y}^{2}\right)$ 는 근육의 중간지점에서 근 섬 유 방향을 따른 두 점이고 $\mathrm{ab}$ 를 연결한 선과 수평축과 이루는 각을 섬유각도(angle 1$)$ 로 정하였다. $\mathrm{c}\left(\mathrm{x}^{3}, \mathrm{y}^{3}\right)$ 와 $\mathrm{d}\left(\mathrm{x}^{4}, \mathrm{y}^{4}\right)$ 는 이미지의 근막을 따른 두 점이고 $\mathrm{cd}$ 를 연결한 선은 근막의 각도(angle 2)를 결정할 수 있다(figurel). 섬유각도는 근막에 대하여 대칭을 이루며 섬유각도 angle 1 에서 angle 2 를 뺀 값으로 정의하였다. ${ }^{24}$

$$
\begin{aligned}
\text { angle1 } & =\operatorname{Tan}^{-1}\left(\frac{y^{2}-y^{1}}{x^{2}-x^{1}}\right) \\
\text { angle2 } & =\operatorname{Tan}^{-1}\left(\frac{y^{4}-y^{3}}{x^{4}-x^{3}}\right) \\
\text { fibreangle } & =\text { angle1 }- \text { angle2 }
\end{aligned}
$$

\section{3) 통계처리}

수집된 자료는 SPSS 12.0 통계 프로그램을 사용하여 모든 측정치 의 평균과 표준편차를 산출했으며, 그룹 내에서 실험 전과 실험 후의 근육 두께와 섬유각도 변화는 paired t-test를 사용하였고, 그룹 간 운 동 효과 비교는 independent t-test를 사용하였다. 모든 통계적 유의 수 준은 $\alpha=0.05$ 로 하였다.

\section{결 과}

\section{1. 배바깥빗근의 두께 변화}

UBEG는 실험 전 $0.37 \pm 0.07$ 에서 실험 후 $0.46 \pm 0.06$ 으로 유의하게 증가되었고 $(\mathrm{p}<0.001), \mathrm{SBEG}$ 는 실험 전 $0.36 \pm 0.09$ 에서 실험 후 $0.42 \pm$ 0.07 로 유의하게 증가되었다 $(\mathrm{p}<0.001)$. 그룹 간 유의한 차이는 없었다 $(\mathrm{p}>0.05)$ (Table 2).

\section{2. 배속빗근의 두께 변화}

$\mathrm{UBEG}$ 는 실험 전 $0.39 \pm 0.14$ 에서 실험 후 $0.63 \pm 0.09$ 로 유의하게 증 가되었고 $(\mathrm{p}<0.001), \mathrm{SBEG}$ 는 실험 전 $0.40 \pm 0.10$ 에서 실험 후 $0.54 \pm 0.15$ 로 유의하게 증가되었다 $(\mathrm{p}<0.05)$. 그룹 간 유의한 차이는 없었다 $(\mathrm{p}>0.05)$ (Table 2). 
Table 2. Comparison of muscle thickness of EO, IO, TrA and fiber angle of ES (unit: EO, IO, TrA-mm, ES- ${ }^{\circ}$ )

\begin{tabular}{llcc}
\hline Muscle & Group & Pre & Post \\
\hline EO & UBEG & $0.37 \pm 0.07$ & $0.46 \pm 0.06^{* * *}$ \\
& SBEG & $0.36 \pm 0.09$ & $0.42 \pm 0.07^{\star * *}$ \\
IO & UBEG & $0.39 \pm 0.14$ & $0.63 \pm 0.09^{* * *}$ \\
& SBEG & $0.40 \pm 0.10$ & $0.54 \pm 0.15^{*}$ \\
TrA & UBEG & $0.27 \pm 0.04$ & $0.36 \pm 0.04^{* \star *}$ \\
& SBEG & $0.27 \pm 0.07$ & $0.35 \pm 0.06^{* * *}$ \\
ES & UBEG & $10.60 \pm 2.41$ & $11.30 \pm 1.83^{* * *}$ \\
& SBEG & $10.90 \pm 2.72$ & $11.40 \pm 1.64^{* * *}$ \\
\hline
\end{tabular}

EO: external oblique, IO: internal oblique, TrA: transverse abdominis, ES: erector spinae, UBEG: unstable bridge exercise group, SBEG: stable bridge exercise group.

*Significant difference within group.

${ }^{*} p<0.05,{ }^{* * *} p<0.001$.

\section{3. 배가로근의 두께 변화}

$\mathrm{UBEG}$ 는 실험 전 $0.27 \pm 0.04$ 에서 실험 후 $0.36 \pm 0.04$ 로 유의하게 증 가되었고 $(\mathrm{p}<0.001), \mathrm{SBEG}$ 는 실험 전 $0.27 \pm 0.07$ 에서 실험 후 $0.35 \pm 0.06$ 으로 유의하게 증가되었다 $(\mathrm{p}<0.001)$. 그룹 간 유의한 차이는 없었다 $(\mathrm{p}>0.05)$ (Table 2).

\section{4. 척추세움근의 섬유각도 변화}

$\mathrm{UBEG}$ 는 실험 전 $10.60 \pm 2.41$ 에서 실험 후 $11.30 \pm 1.83$ 으로 유의하게 증가되었고, $\mathrm{SBEG}$ 는 실험 전 $10.90 \pm 2.72$ 에서 $11.40 \pm 1.64$ 로 유의하게 증가되었다 $(\mathrm{p}<0.001)$. 그룹 간 유의한 차이는 없었다 $(\mathrm{p}>0.05)$ (Table 2).

\section{고 찰}

몸통 안정성은 분절 근육들의 활동증가로 유지되고 활동을 하는 동안 큰 몸통 근육들과 작은 내재근(intrinsic muscle) 사이의 조화로 운 근육 동원을 위한 운동조절로서 유지된다. ${ }^{34}$ 그러므로 척추의 불 안전성은 몸통 안정화 근육의 불충분한 근력과 지구력, 몸통과 배 근 육의 부적절한 동원 때문에, ${ }^{35}$ 몸통 근육들의 구조적 변형을 일으키 게 된다. ${ }^{36}$ 그 결과 배 근육들과 척추 세움근의 근력이 약해져서 ${ }^{1}$ 근육 뼈대계 질환으로 진행되며 일상생활에 영향을 미치게 된다. 척추분 절의 불안정성 해결을 위해 척추분절의 동적인 안정성 제공에 중요 한 역할을 하는 몸통 주위에 근육들의 불균형을 맞추는 것이 중요하 다. ${ }^{37}$ 안정화 운동은 관절의 무리가 없는 범위에서 근육과 관절막, 인 대, 및 힘줄의 움직임 조절능력을 회복시키는 데 목적이 있으며, 현재 는 근육뼈대계 질환, 수술 후 재활치료에 필수적인 방법이다. 몸통의 크고 작은 근육들이 안정성에 밀접한 영향을 미치는 것이 증명되었 으며, 신체 동작이 일어나거나 부하가 적용될 때 척추의 안정성을 위 해 동시에 작용한다. ${ }^{38}$
이에 본 연구자는 허리 안정화 운동 중에서 효과적으로 보고되고 있는 교각운동(bridging exercise) $)^{6-8}$ 을 지지면을 다르게 훈련 한 후 배 바깥빗근, 배속빗근, 배가로근의 근 두께와 척추세움근의 섬유각도 에 미치는 영향을 알아본 결과 배바깥빗근, 배속빗근, 배가로근의 두 께 변화는 불안정 지지면에서의 교각 운동군과 안정적 지지면에서의 교각 운동군 모두 실험 전에 비해 실험 후에 통계적으로 유의하게 증 가하였다.

이것은 요통 환자에게 4주간 안정화 운동과 근력강화 운동을 실시 한 결과 두 그룹 모두 근육 두께가 증가하였고, 특히 안정화 운동이 근력강화 운동에서보다 심부 안정화 근육인 배가로근과 뭇갈래근의 근 두께 증가 ${ }^{25}$ 를 보고한 것과 유사한 결과이다. $\operatorname{Lim}$ 과 $\mathrm{Kim}^{26}$ 의 연구 에서도 편평한 지지면과 불안정한 지지면에서 허리 안정화 운동을 시행했을 때 두 운동 모두가 만성 뇌졸중 환자의 균형능력 향상이 있 었지만, 불안정한 지지면에서 운동을 할 때가 몸의 흔들림이 더 커지 면서 이를 바로 잡기 위한 허리 안정화 근육들이 더 활성화 되기 때 문에 균형능력 증진에 더 효과적이라고 하였으며, Vera-Garcia 등 ${ }^{27}$ 과 Lehman 등 ${ }^{28}$ 또한 불안정 지지면에서의 몸통 안정화 운동이 안정면 보다 몸통 근육의 활성도와 두께가 더 증가되었다고 하여 본 연구의 결과를 지지하고 있다. 따라서 본 연구의 근 두께 증가는 약화된 근력 이 향상됨을 의미하고 요통환자의 허리부위 안정성에 영향을 주어 요통 개선에 도움을 줄 수 있다는 것을 알 수 있었다.

두 그룹 간에 통계적으로 유의성이 없다는 결과를 뒷받침 할 연구 로 몸통 근육의 활성도 변화, ${ }^{39}$ 배가로근의 두께 변화, ${ }^{29}$ 몸통 깊은 근 육의 변화 ${ }^{30}$ 가 지지면의 차이에 따른 안정화 운동에 영향을 미치지 않는다고 하였으며, Lee 등 ${ }^{40}$ 도 안정적 지지면에서 보다 불안전 지지 면에서 교각운동을 시행할 때 원위부인 발에서 전-후, 좌-우의 불안 정을 극복하기 위해 반힘줄근과 넙다리두갈래근은 무릎관절 굽힘 과 더불어 엉덩관절 폄근으로 작용하고, 장딴지근 내측은 발목관절 을 조절하여 교각자세를 유지하기 위해작용하여 불안정 지지면에서 몸통 깊은근에 영향을 덜 미칠 것이라 하였다.

척추 세움근의 섬유의 각도는 나이가 들수록 작아진다고 보고되 고 있는데, 이것은 나이가 들어감에 따른 척추 앞 굽이가 감소하는 것 이 첫 번째 이유이며 다른 요인들로는 굽힘 되는 자세와 척추 세움근 의 근육의 크기가 감소하는 것들을 들 수 있다. ${ }^{41,42}$ 본 연구 결과, 척추 세움근의 섬유각도 변화는 불안정 지지면에서의 교각 운동군과 안 정적 지지면에서의 교각 운동군 모두 실험 전에 비해 실험 후에 통계 적으로 유의하게 증가하여, 허리부위의 안정화에 영향을 미쳐 허리 통증 환자에게 효과적인 운동법임을 확인하였다.

본 연구는 특정 연령층을 대상으로 하였고 대상자 수가 너무 적어 다양한 연령층에게 이 연구 결과를 일반화하여 해석하기에는 무리 가 있지만 요통의 해결방안을 연구하는데 기초자료와 임상에서 요 
통의 예방을 위한 운동방법으로 유용할 것으로 보인다. 향후 대상자 수를 늘리고 다양한 연령층에 따른 효과를 비교하여 요통 환자의 중 재 방법으로 근거를 제시할 수 있을 것으로 생각된다.

\section{참고 문헌}

1. Hodges PW, Moseley GL. Pain and motor control of the lumbopelvic region: effect and possible mechanisms. J Electromyogr Kinesiol. 2003;13(4):361-70.

2. Stevens VK, Bouche KG, Mahieu NN et al. Trunk muscle activity in healthy subjects during bridging stabilization exercises. BMC Musculoskelet Disord. 2006;7(1):75.

3. Kankaanpää M, Colier WN, Taimela S et al. Back extensor muscle oxygenation and fatigability in healthy subjects and low back pain patients during dynamic back extension exertion. Pathophysiology. 2005;12(4): $267-73$.

4. Norris C. Functional load abdominal training: part 1. J Bodyw Mov Ther. 1999;3(3):29-39.

5. Hubley-Kozey CL, Vezina MJ. Muscle activation during exercises to improve trunk stability in men with low back pain. Arch Phys Med Rehabil. 2002;83(8):1100-8.

6. Song GB, Heo JY. The effects of bridge exercise with abdominal drawingin on balance in patients with stroke. J Kor Phys Ther. 2016;28(1):1-7.

7. Koh EK, Jang JH, Jung DY. Effect of abdominal hollowing on muscle activity of gluteus maximus and erector spinae during bridging exercise. J Kor Phys Ther. 2012;24(5):319-24.

8. Kim JH, Kim Y, Chung YJ. The influence of an unstable surface on trunk and lower extremity muscle activities during variable bridging exercises. J Phys Ther Sci. 2014;26(4):521.

9. O'Sullivan PB, Phyty GDM, Twomey LT et al. Evaluation of specific stabilizing exercise in thetreatment of chronic low back pain with radiologic diagnosis of spondylolysis or spondylolist hesis. Spine. 1997;22(24): 2959-67.

10. Haynes W. Core stability and the unstable platform device. J Bodyw Mov Ther. 2004;8(2):88-103.

11. Melnick M. Therapeutic exercise: moving toward function. Journal of Physical Therapy Education. 1999;13(2):56.

12. Alway SE, Stray-Gundersen J, Grumbt WH et al. Muscle cross-sectional area and torque in resistance-trained subjects. European journal of applied physiology and occupational physiology. 1990;60(2):86-90.

13. Narici M, Landoni L, Minetti A. Assessment of human knee extensor muscles stress from in vivo physiological cross-sectional area and strength measurements. European journal of applied physiology and occupational physiology. 1992;65(5):438-44.

14. Nuttera J, Thorland WG. Body composition and anthropometric correlates of isokinetic leg extension strength of young adult males. Research Quarterly for Exercise and Sport. 1987;58(1):47-51.

15. Vandervoort AA. Ankle mobility and postural stability. Physiotherapy theory and practice. 1999;15(2):91-103.

16. Gollnick PD, Parsons D, Riedy M et al. Fiber number and size in overloaded chicken anterior latissimus dorsi muscle. Journal of Applied Physiology. 1983;54(5):1292-7.
17. Kawakami Y, Ichinose Y, Kubo K et al. Architecture of contracting human muscles and its functional significance. Journal of Applied Biomechanics. 2000;16(1):88-97.

18. Bilodeau M, Schindler-Ivens S, Williams DM et al. EMG frequency content changes with increasing force and during fatigue in the quadriceps femoris muscle of men and women. Journal of electromyography and kinesiology: official journal of the International Society of Electrophysiological Kinesiology. 2003;13(1):83-92.

19. Rankin G, Stokes M, Newham D. Size and shape of the posterior neck muscles measured by ultrasound imaging: normal values in males and females of different ages. Man Ther. 2005;10(2):108-15.

20. Chi-Fishman G, Hicks JE, Cintas HM et al. Ultrasound imaging distinguishes between normal and weak muscle. Arch Phys Med Rehabil. 2004;85(6):980-6.

21. McMeeken J, Beith I, Newham D et al. The relationship between EMG and change in thickness of transversus abdominis. Clin Biomech. 2004;19(4):337-42.

22. Christensen L, Djurhuus J, Constantinou C. Imaging of pelvic floor contractions using MRI. Neurourol Urodyn. 1995;14(3):209-16.

23. McGill SM, Hughson RL, Parks K. Changes in lumbar lordosis modify the role of the extensor muscles. Clin Biomech. 2000;15(10):777-80.

24. Singh DK, Bailey M, Lee RY. Ageing modifies the fibre angle and biomechanical function of the lumbar extensor muscles. Clin Biomech. 2011;26(6):543-7.

25. Jeong CJ, Yang HS, Yoo YD et al. The effect of stabilization exercise and strength exercise onpain, rom, strength, muscle thickness of non-specific low back patients. Journal of The Kor ean Society of Integrative Medicine. 2014;2(1):35-49.

26. Lim J, Kim D. The Changes of lumbar stabilization exercise on balance with a variety of supporting surface in chronic hemiplegia. Journal of The Korean Society of Integrative Medicine. 2015;3(3):9-16.

27. Vera-Garcia FJ, Grenier SG, McGill SM. Abdominal muscle response during curl-ups on both stable and labile surfaces. Phys Ther. 2000; 80(6):564-9.

28. Lehman GJ, Hoda W, Oliver S. Trunk muscle activity during bridging exercises on and off a swissball. Chiropractic \& osteopathy. 2005;13(1):1.

29. Saliba SA, Croy T, Guthrie R et al. Differences in transverse abdominis activation with stable and unstable bridging exercises in individuals with low back pain. North American Journal of Sports Physical Therapy : NAJSPT. 2010;5(2):63-73.

30. Imai A, Kaneoka K, Okubo Y et al. Trunk muscle activity during lumbar stabilization exercises on both a stable and unstable surface. J Orthop Sports Phys Ther. 2010;40(6):369-75.

31. Bae W, Lee K. Effect of the breathing methods in accordance with surfaces during bridging exercises. Korean Society of Physical Medicine. 2016;11(2):33-40.

32. Hodges PW, Gandevia SC. Changes in intra-abdominal pressure during postural and respiratory activation of the human diaphragm. J Appl Physiol. 2000;89(3):967-76.

33. Gong WT. Correlations between transversus abdominis thickness, lumbar stability, and balance of female university students. J Phys Ther Sci. 2013;25(6):681-3.

34. Behm DG, Anderson K, CURNEW RS. Muscle force and activation under stable and unstable conditions. J Strength Cond Res. 2002;16(3):416-22. 
35. Vezina MJ, Hubley-Kozey CL. Muscle activation in therapeutic exercises to improve trunk stability. Arch Phys Med Rehabil. 2000;81(10):1370-9.

36. Newcomer KL, Laskowski ER, Yu B et al. Differences in repositioning error among patients with low back pain compared with control subjects. Spine. 2000;25(19):2488-93.

37. Panjabi MM. Clinical spinal instability and low back pain. J Electromyogr Kinesiol. 2003;13(4):371-9.

38. Cholewicki J, McGill SM. Mechanical stability of the in vivo lumbar spine: implications for injury and chronic low back pain. Clin Biomech. 1996;11(1):1-15.

39. Marshall PW, Murphy BA. Core stability exercises on and off a Swiss ball. Arch Phys Med Rehabil. 2005;86(2):242-9.

40. Lee S, Kim T, Cynn H et al. The influence of unstability of supporting surface on trunk and lower extremity muscle activities during bridging exercise combined with core-stabilization exercise. Physical Therapy Korea. 2010;17(1):17-25.

41. Aagaard P, Suetta C, Caserotti P et al. Role of the nervous system in sarcopenia and muscle atrophy with aging: strength training as a countermeasure. Scand J Med Sci Sports. 2010;20(1):49-64.

42. Ostrowska B. The shape of anterior-posterior spinal curvature in postmenopausal women with osteoporosis. Ortopedia, traumatologia, rehabilitacja. 2006;8(5):537-42. 